Transurethral cystoscopy (CS) is a common urological procedure, performed mostly for diagnostic but also for therapeutic purposes. Although CS is generally well tolerated, some patients describe the pain related to the procedure as high or even "unbearable". As a result, many patients fear and avoid both primary and/or follow-up cystoscopies. This may lead to uncontrolled progression of neoplastic disease. Therefore, it is crucial to maximally increase the comfort of the patient and to implement safe and effective analgesia before the procedure. Providing the patients with appropriate care during CS can encourage them to comply with diagnostic schedules and improve their prognosis. The aim of this review is to analyze the available literature on various methods of pain reduction during transurethral CS. The PubMed electronic database limited to English articles published until January 2021 was used in the process. Meta-analyses, systematic reviews, randomized controlled trials, clinical trials, prospective randomized studies, multicenter comparisons, reviews and retrospective comparisons were used. As a result, 65 articles were included in this review.

Key words: cystoscopy, pain reduction, transurethral cystoscopy, rigid cystoscopy, flexible cystoscopy.

Contemp Oncol (Pozn) 2020; 24 (4): 80-87 DOI: https://doi.org/10.5114/wo.2021.106652

\section{Pain reduction methods during transurethral cystoscopy}

\author{
Jan Łaszkiewicz ${ }^{1}$, Wojciech Krajewski², Mateusz Łuczak², Joanna Chorbińska ${ }^{2}$, \\ Łukasz Nowak ${ }^{2}$, Klaudia Bardowska², Romuald Zdrojowy ${ }^{2}$
}

${ }^{1}$ Medical University of Lodz, Lodz, Poland

${ }^{2}$ Department of Urology and Oncologic Urology, Wroclaw Medical University, Wroclaw, Poland

\section{Introduction}

Transurethral cystoscopy (CS) is a common urologic procedure, performed mostly for diagnosis of bladder cancer [1]. General indications for this procedure include hematuria (micro- and macroscopic), morphologic abnormalities of the bladder, trauma, foreign body removal, urinary incontinence, lower urinary tract symptoms, chronic urinary tract infections, hematospermia and azoospermia [1, 2].

There are two main types of instruments used for CS - rigid and flexible. The latter is considered to be generally less burdensome for the patient, while maintaining the comparable efficacy with rigid CS in the majority of purely diagnostic procedures [3]. However, rigid CS offers a wider working channel lumen and is essential in more demanding inpatient procedures [4, 5].

Cystoscopy is performed after standard physical examination, disinfection of external genitalia and intraurethral instillation of some form of lubricant [6]. In the majority of cases, no general anesthesia is required.

Even though CS is considered safe, complications such as hematuria (19\%), dysuria (50\%), frequency (37\%), and urinary tract infection (2-3\%) may occur $[1,7]$. These problems are usually short-term, self-limiting and mild [6]. The risk of more serious complications, such as urethral damage and further stricture, severe infections and acute urinary retention, is extremely low $[1,6]$.

Cystoscopy, like any other invasive procedure, may cause pain, discomfort and stress in both men and women [8]. Greenstein et al. used a Visual Analog Pain Scale (VAS, 0-10 cm) in order to measure patients' discomfort during CS. They analyzed 1320 procedures and found that rigid CS caused significantly more pain in men $(3.4 \pm 1.6)$ and women $(2.5 \pm 1.6)$ than flexible CS $(2.5 \pm 1.4$ and $1.1 \pm 1.9$ respectively) [9]. Other studies also showed that rigid CS was less likely to be pain-free and could be even two times more painful than flexible CS $[3,4,10]$. It is worth emphasizing that undergoing first CS is a strong predictive factor for significant pain, probably because of increased preprocedural stress, anxiety and fear [9]. Also, preprocedural fear causes that patients who are listed for CS anticipate much worse pain compared to the pain they actually experience during the further procedure [2, 8].

In the majority of studies, males report significantly higher levels of perioperative pain than women. This is mainly caused by evident anatomical differences between the two sexes, as well as possible psychological and sociological issues. It should also be remembered that although CS is generally well tolerated, some patients describe pain related to the procedure as "unbearable" [4]. In consequence, many patients fear and avoid primary and/ or follow-up cystoscopies. This may lead to uncontrolled progression of the disease. Providing the patients with appropriate care during CS can encourage them to comply with diagnostic schedules and improve their prognosis.

\section{Evidence acquisition}

The PubMed electronic database limited to English articles published until January 2021 was used in the process. Search terms included: "cystoscopy 
pain", "cystoscopy pain reduction", "rigid cystoscopy pain reduction", "flexible cystoscopy pain reduction", "cystoscopy analgesia", along with free text, related, derivative and exploded terms. Meta-analyses, systematic reviews, randomized controlled trials, clinical trials, prospective randomized studies, multicenter comparisons, reviews and retrospective comparisons were used. As a result, 65 articles were included in this review (Fig. 1].

\section{Lidocaine gel}

Topical lidocaine gel is the most popular form of anesthesia during CS. In theory, lidocaine gel lubricates and provides local analgesia in the urethra by inhibiting membrane voltage-gated sodium channels, thus blocking neurotransmission. However, despite many years of clinical implementation, there is still no consensus whether it reduces pain more than plain lubricating gel (Table 1).

\section{Lidocaine gel in flexible cystoscopy}

A meta-analysis that included 14 studies published by Aaronson et al. in 2009 stated that intraurethral lidocaine gel injection increased comfort in men undergoing flexible CS [11]. This result was supported by Raskolnikov et al. in the most recent meta-analysis from 2019 [12]. On the other hand, after implementing slightly different inclusion criteria and statistical methods, Patel, Jones and Babineau stated that there was no difference in pain levels between lidocaine gel and plain lubricating gel during the procedure in men [13]. All of these meta-analyses used VAS scores if they were given. A variety of papers also proved that lidocaine gel does not reduce pain perception [14-16]. In women, Dougher et al. stated that lidocaine gel provided pain relief, while Rappaport et al. did not observe any beneficial influence (based on VAS scores) $[17,18]$. What is more, Carrion et al. stated that the procedures performed only with irrigation solution as a lubricant were not more uncomfortable for the patients [19] (Table 2).

\section{Lidocaine gel in rigid cystoscopy}

Data regarding lidocaine gel use in rigid CS is scarce. Nonetheless, most of the available papers suggest that

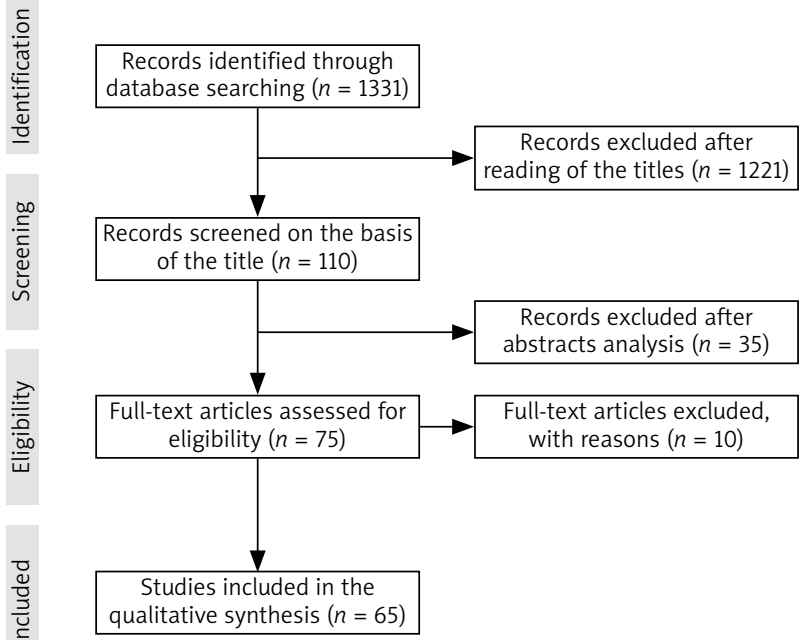

Fig. 1. PRISMA flow chart of study selection process

its instillation before the procedure may decrease pain in men, but has no effect in women (based on VAS scores) [18, 20-22]. In women, intraurethral instillation of lidocaine gel was compared with direct application of lidocaine spray. Both agents lowered pain levels, but the delivery of lidocaine spray caused a mild discomfort [23] (Table 2). Other authors stated that adding dimethyl sulfoxide to lidocaine provided better anesthesia in men than lidocaine alone [24] (Table 2). Moreover, male patients might benefit from intraurethral instillation of lidocaine gel alkalized with $\mathrm{NaHCO}_{3}$ solution (Table 2). Alkalized lidocaine improves neural blockade and speeds up its onset time by facilitating the diffusion of lidocaine [25].

\section{Dwell time of lidocaine gel}

It was hypothesized that lidocaine gel is only helpful in decreasing pain in men if there is enough time between the administration of the gel and the onset of the procedure (Table 3). Studies showed that allowing the gel to dwell for 10 to 20 minutes before CS may be enough for lidocaine to diffuse through the mucosa [20, 22, 26, 27].

Table 1. Lidocaine gel in pain reduction during cystoscopy compared to plain lubricant

\begin{tabular}{|c|c|c|c|c|c|c|}
\hline $\begin{array}{l}\text { Name of first } \\
\text { author }\end{array}$ & $\begin{array}{c}\text { Year } \\
\text { of publication }\end{array}$ & $\begin{array}{c}\text { Type } \\
\text { of article }\end{array}$ & $\begin{array}{l}\text { Number } \\
\text { of patients }\end{array}$ & Gender & $\begin{array}{c}\text { Type } \\
\text { of cystoscopy }\end{array}$ & $\begin{array}{c}\text { Significant } \\
\text { pain reduction }\end{array}$ \\
\hline Aaronson [11] & 2009 & Meta-analysis & 411 & Men & Flexible & Yes \\
\hline Raskolnikov [12] & 2019 & Meta-analysis & 1549 & Men & Flexible & Yes \\
\hline Patel [13] & 2008 & Meta-analysis & 817 & Men & Flexible & No \\
\hline Chitale [14] & 2008 & Randomized controlled trial & 51 & Men & Flexible & No \\
\hline Akkoç [15] & 2016 & Retrospective comparison & 220 & Men & Flexible & No \\
\hline Cano-Garcia [16] & 2015 & Observational study & 72 & Both & Flexible & No \\
\hline Dougher [17] & 2019 & Randomized controlled trial & 116 & Women & Flexible & Yes \\
\hline Rappaport [18] & 2020 & Prospective randomized study & 120 & Women & Both & No \\
\hline Goldfischer [20] & 1997 & Clinical trial & 179 & Both & Rigid & $\begin{array}{c}\text { Men - Yes } \\
\text { Women - No }\end{array}$ \\
\hline Goktug [21] & 2014 & Randomized controlled trial & 320 & Men & Rigid & Yes \\
\hline Vasudeva [22] & 2014 & Randomized controlled trial & 400 & Men & Rigid & Yes \\
\hline
\end{tabular}


Table 2. Lubricant characteristics in pain reduction during cystoscopy

\begin{tabular}{|c|c|c|c|c|c|c|c|}
\hline Method & Compared to & $\begin{array}{c}\text { Name of first } \\
\text { author }\end{array}$ & $\begin{array}{c}\text { Year } \\
\text { of publication }\end{array}$ & $\begin{array}{c}\text { Number } \\
\text { of patients }\end{array}$ & Gender & $\begin{array}{c}\text { Type } \\
\text { of cystoscopy }\end{array}$ & $\begin{array}{c}\text { Significant } \\
\text { pain reduction }\end{array}$ \\
\hline $\begin{array}{l}\text { Lubrication of } \\
\text { the urethra }\end{array}$ & Saline solution & Carrion [19] & 2016 & 100 & Men & Flexible & No \\
\hline Lidocaine spray & $\begin{array}{c}\text { Aqueous } \\
\text { lubricating gel }\end{array}$ & Choe [23] & 2008 & 144 & Women & Rigid & Yes \\
\hline Lidocaine spray & Lidocaine gel & Choe [23] & 2008 & 144 & Women & Rigid & No \\
\hline $\begin{array}{l}\text { Dimethyl } \\
\text { sulfoxide + } \\
\text { lidocaine gel }\end{array}$ & Lidocaine gel & Demir [24] & 2008 & 140 & Men & Rigid & Yes \\
\hline $\begin{array}{l}\text { NaHCO3 buffered } \\
\text { lidocaine gel }\end{array}$ & Lidocaine gel & $\mathrm{Li}[25]$ & 2016 & 60 & Men & Rigid & Yes \\
\hline $\begin{array}{l}20 \mathrm{ml} \text { of } \\
\text { lidocaine gel }\end{array}$ & $\begin{array}{c}10 \mathrm{ml} \text { of } \\
\text { lidocaine gel }\end{array}$ & Holmes [27] & 2001 & 147 & Men & Flexible & Yes \\
\hline $\begin{array}{l}20 \mathrm{ml} \text { of } \\
\text { lidocaine gel }\end{array}$ & $\begin{array}{c}10 \mathrm{ml} \text { of } \\
\text { lidocaine gel }\end{array}$ & McFarlane [31] & 2001 & 60 & Men & Flexible & No \\
\hline $\begin{array}{l}4 \text { degrees C } \\
\text { lidocaine gel }\end{array}$ & $\begin{array}{l}22 \text { degrees } C \\
\text { lidocaine gel }\end{array}$ & $\begin{array}{c}\text { Thompson } \\
\text { [33] }\end{array}$ & 1999 & 60 & Men & No data & Yes \\
\hline $\begin{array}{l}4 \text { degrees C } \\
\text { lidocaine gel }\end{array}$ & $\begin{array}{l}22 \text { degrees } C \\
\text { lidocaine gel }\end{array}$ & Goel [34] & 2003 & 40 & Men & No data & Yes \\
\hline $\begin{array}{l}10 \text { seconds } \\
\text { instillation of } \\
\text { lidocaine gel }\end{array}$ & $\begin{array}{l}2 \text { seconds } \\
\text { instillation of } \\
\text { lidocaine gel }\end{array}$ & Khan [35] & 2002 & 100 & Men & No data & Yes \\
\hline
\end{tabular}

According to Vasudeva et al. and Choong et al., 15 minutes was the most favorable time of lidocaine dwell time $[22,26]$. Importantly, starting the CS only 5 minutes or less after the instillation of the gel did not provide sufficient pain relief $[28,29]$. However, some articles suggest that there was no difference whatsoever between instant and delayed cystoscopies [30].

\section{Other properties of lidocaine gel}

There is no consensus whether the volume of lidocaine gel has an influence on patients' comfort. Holmes et al. found that $20 \mathrm{ml}$ is more advantageous than $10 \mathrm{ml}$, while McFarlane et al. did not observe any difference in pain perception between $10 \mathrm{ml}$ and $20 \mathrm{ml}$ of lidocaine gel (based on VAS scores) [27, 31] (Table 2). Moreover, Ho et al. suggested that the intraurethral injection of lidocaine gel can actually be more painful than the injection of plain gel, due to the chemical composition of lidocaine-based lubricant [32]. Regardless, it has been proven that in order to maximize the patient's comfort during the administration of the gel, it should be cold (ideally 4 degrees Celsius) and instilled slowly (over 10 seconds) [33-35] (Table 2).
In conclusion, lidocaine gel efficacy remains controversial, but it should be used as long as it is undoubtedly proven ineffective. In order to increase the chances of pain reduction $\mathrm{NaHCO}_{3}$ or dimethyl sulfoxide can be added to the gel. It is crucial to slowly inject 10-20 ml of cold gel and wait some time before commencing the procedure.

\section{Urination and high irrigation pressure}

The time of the highest discomfort in men is when the cystoscope is passing through the external urethral sphincter [36-38]. It was hypothesized that micturition during cystoscope passage and/or increased hydrostatic pressure of the irrigation solution might serve a major role in reducing the discomfort associated with this part of the procedure in male patients (Table 4).

It has been proven that instructing the patient to urinate causes the external urethral sphincter to relax, thus opening the membranous urethra and facilitating scope passage [36]. The male patients who micturated during the insertion of the scope reported lower pain levels (VAS score and Hamilton Anxiety Rating Scale) [36, 37].

Table 3. Influence of dwell time of lidocaine gel in pain reduction during cystoscopy

\begin{tabular}{|c|c|c|c|c|c|c|}
\hline Retention time & Name of first author & $\begin{array}{c}\text { Year } \\
\text { of publication }\end{array}$ & $\begin{array}{c}\text { Number } \\
\text { of patients }\end{array}$ & Gender & $\begin{array}{c}\text { Type } \\
\text { of cystoscopy }\end{array}$ & $\begin{array}{c}\text { Significant } \\
\text { pain reduction }\end{array}$ \\
\hline 15 minutes & Vasudeva [22] & 2014 & 400 & Men & Rigid & Yes \\
\hline 15 minutes & Choong [26] & 1997 & 90 & Men & Flexible & Yes \\
\hline 5 minutes & Panach-Navarette [28] & 2015 & 242 & Men & Flexible & No \\
\hline 3 minutes & Losco [29] & 2011 & 50 & Men & Flexible & No \\
\hline No data & Herr [30] & 2001 & 288 & Men & Flexible & No \\
\hline
\end{tabular}


Table 4. Urination and high irrigation pressure in pain reduction during cystoscopy

\begin{tabular}{|c|c|c|c|c|c|c|}
\hline Method & $\begin{array}{c}\text { Name of first } \\
\text { author }\end{array}$ & $\begin{array}{c}\text { Year } \\
\text { of publication }\end{array}$ & $\begin{array}{c}\text { Number } \\
\text { of patients }\end{array}$ & Gender & $\begin{array}{c}\text { Type } \\
\text { of cystoscopy }\end{array}$ & $\begin{array}{l}\text { Significant pain } \\
\text { reduction }\end{array}$ \\
\hline Urination & Xie [36] & 2020 & 96 & Men & Flexible & Yes \\
\hline Urination & Sarkar [37] & 2019 & 100 & Men & Rigid & Yes \\
\hline Bag squeeze & Gunendran [38] & 2008 & 151 & Men & Flexible & Yes \\
\hline High irrigation pressure & Zhang [39] & 2015 & 168 & Men & Flexible & Yes \\
\hline Bag squeeze & Berajoui [40] & 2020 & 200 & Men & Flexible & Yes \\
\hline
\end{tabular}

Another method of pain reduction for male patients may be the "bag squeeze" technique, which aims to create high irrigation pressure while passing the cystoscope [38]. Essentially, increased hydrostatic pressure of the irrigation solution serves to widen the urethra and to relax the external urethral sphincter. Again, this facilitates cystoscope insertion, which significantly reduces the discomfort (based on the VAS score) [38]. Independent studies from 2008, 2015 and 2020 unanimously confirmed that increased irrigation pressure during flexible CS was associated with lower pain levels in male patients [38-40]. Zhang et al. suggested that placing the irrigation solution bag $150 \mathrm{~cm}$ over the patient's bed was more advantageous than squeezing the bag, because it maintained high and more consistent pressure, as well as eliminating the need for an additional assistant [39]. In conclusion, urination and "bag squeeze" are simple, free and effective ways that increase male patients' comfort during CS.

\section{Nitrous oxide}

Nitrous oxide $\left(\mathrm{N}_{2} \mathrm{O}\right)$ is a fast-acting anesthetic and sedative known for its short-term action with few adverse effects. Nitrous oxide inhalation is often used in simple dental and pediatric procedures, but it can also be used in a variety of outpatient procedures [41]. There are, however, some contraindications to its use, such as intoxication resulting in hemodynamic instability, high intracranial pressure, bowel obstruction and pneumothorax [41].

Calleary et al. recruited 69 men into a study on the effect of Entonox (50\% nitrous oxide and 50\% oxygen) inhalation for 3 minutes before flexible CS. The Entonox group showed lower VAS scores, as well as a decreased pulse rate [42]. In other studies, $\mathrm{N}_{2} \mathrm{O}$ has been proven to provide a significant decrease of pain levels during CS, as well as during other outpatient urological procedures, such as prostate biopsy, ureteral stent placement and extracorporeal shockwave lithotripsy [41-43].

\section{Distractions}

Distracting the patients might be beneficial in lowering pain perception during CS [44]. Numerous methods can be used to shift patients' focus away from the procedure. The most commonly used ones include real-time visualization of endoscopic view, music, movies, virtual reality and use of a "stress ball" [44-46] (Table 5).

According to González-Padilla et al., allowing patients to watch their flexible CS on the screen was beneficial in women [47]. On the other hand, Patel, Jones and Bubineau claimed that there was no significant pain relief in women viewing their rigid CS [48]. Both research groups used

Table 5. Distractions in pain reduction during cystoscopy

\begin{tabular}{|c|c|c|c|c|c|c|}
\hline Method & Name of first author & $\begin{array}{c}\text { Year } \\
\text { of publication }\end{array}$ & $\begin{array}{l}\text { Number } \\
\text { of patients }\end{array}$ & Gender & $\begin{array}{c}\text { Type } \\
\text { of cystoscopy }\end{array}$ & $\begin{array}{l}\text { Significant pain } \\
\text { reduction }\end{array}$ \\
\hline $\begin{array}{l}\text { Real-time visualization } \\
\text { and music }\end{array}$ & Gupta [44] & 2019 & 200 & Both & Rigid & Yes \\
\hline Video, music, stress ball & Gezginci [45] & 2018 & 120 & Men & Rigid & Yes \\
\hline Virtual reality & Walker [46] & 2014 & 45 & Men & Flexible & No \\
\hline Real-time visualization & González-Padilla [47] & 2019 & 404 & Both & $\begin{array}{l}\text { Men - Flexible } \\
\text { Women - Rigid }\end{array}$ & $\begin{array}{c}\text { Men - No } \\
\text { Women - Yes }\end{array}$ \\
\hline Real-time visualization & Patel [48] & 2008 & 100 & Women & Rigid & No \\
\hline Real-time visualization & Zhang [49] & 2011 & 86 & Men & Flexible & Yes \\
\hline Real-time visualization & Soomro [50] & 2011 & 76 & Men & Flexible & Yes \\
\hline Real-time visualization & Patel [51] & 2007 & 100 & Men & Flexible & Yes \\
\hline Real-time visualization & Cornel [52] & 2008 & 154 & Men & Flexible & No \\
\hline Real-time visualization & Kesari [53] & 2003 & 51 & Both & Rigid & No \\
\hline Music & García-Perdomo [54] & 2018 & No data & No data & Both & Yes \\
\hline Music & Kyriakides [55] & 2018 & 331 & No data & Both & Yes \\
\hline Binaural beats & Ölçücü [56] & 2021 & 252 & Men & Flexible & Yes \\
\hline Video & Gezginci [57] & 2020 & 60 & Women & Rigid & Yes \\
\hline
\end{tabular}


VAS scores to assess the pain. Many articles showed divergent results - majority of them claimed that self-visualization significantly reduced discomfort [44, 49-51], while a few studies proved the method to be inefficient $[52,53]$. Even though no definite conclusion about the efficacy of real-time self-visualization during CS can be made, it still should be implemented as a free and easy method that may reduce pain perception.

Listening to music is another well-researched method that can increase patients' comfort. Two recent meta-analyses proved that listening to classical/folk/popular music could be beneficial in urological outpatient procedures, including CS $[54,55]$. Listening to pure binaural beats (exposing each ear to two sounds of different frequencies, but steady intensity) might have a positive influence too. According to Ölçücü et al., binaural beats cause the brain's dominant wave frequency to synchronize with these sounds, which might reduce patients' anxiety during CS [56].

A few articles focused on movies and one study used VR as a distraction. The studies showed that watching a relaxing movie reduced the pain in rigid CS in both men and women $[45,57]$. On the other hand, VR did not alleviate the pain in men undergoing flexible CS [46]. These studies used VAS scores, State-Trait Anxiety Inventory (STAI) and hemodynamic parameters.

Lastly, the direct comparison of different distraction methods favored the video as the one with the most positive influence on patients' comfort [45].

It is worth noting that combining different distractions at the same time provided greater pain reduction than using only a single distraction [44].

\section{Pharmacotherapy}

Despite the existence of numerous efficient analgesic drugs, their administration prior to CS is not common. Many studies have been conducted on a variety of drugs and their influence on pain reduction during CS (Table 6).
It has been proven that premedication of different non-steroidal anti-inflammatory drugs (NSAIDs) is effective in CS. For example, oral and intrarectal diclofenac, oral zaltoprofen and intramuscular parecoxib administration before the procedure all decreased pain associated with CS (based on VAS scores) [58-61]. That is why it is safe to assume that the majority of NSAIDs, regardless of the way of administration, can increase patients' comfort during CS. Anti-inflammatory drugs, however, can cause various adverse effects, including gastrointestinal ulceration and higher risk of bleeding [58]. Therefore, NSAIDs are contraindicated in patients with peptic ulcer disease, bleeding diatheses, renal insufficiencies and aspirin hypersensitivity.

Benzodiazepines are the second group of medications that can be used in order to lower the pain levels during CS. Pre-operative midazolam and alprazolam are highly effective not only in pain management but also in anxiety reduction (based on VAS and STAI) [62, 63]. Generally, these benzodiazepines are safe and well tolerated by the patients, but possible side effects include respiratory depression [62-64]. That is why midazolam and alprazolam should not be used in patients with myasthenia gravis, chronic obstructive pulmonary disease, bronchitis and sleep apnea. Arpaci and Bozkirli used a combination of midazolam and remifentanil, achieving sufficient pain reduction, while suggesting that dexmedetomidine-remifentanil is a superior drug combination [64]. Dexmedetomidine does not cause respiratory depression in therapeutic doses, while the same adverse effect is the most dangerous in remifentanil use [64]. Therefore, remifentanil cannot be administered in patients with respiratory instability.

Ketamine can also be used in order to manage the pain during CS. Moharari et al. proposed an interesting approach of intraurethral injection of $100 \mathrm{mg}$ of ketamine mixed with $10 \mathrm{ml}$ of $2 \%$ lidocaine gel before the CS [65]. The results of the study were satisfactory, but the technique was criticized, due to possible ketamine related cystitis [66]. That is why intraurethral injection of ketamine

Table 6. Drugs in pain reduction during or after cystoscopy

\begin{tabular}{|c|c|c|c|c|c|c|c|}
\hline Drug & $\begin{array}{c}\text { Way of } \\
\text { administration }\end{array}$ & $\begin{array}{c}\text { Name of first } \\
\text { author }\end{array}$ & $\begin{array}{c}\text { Year } \\
\text { of publication }\end{array}$ & $\begin{array}{l}\text { Number } \\
\text { of patients }\end{array}$ & Gender & $\begin{array}{c}\text { Type } \\
\text { of cystoscopy }\end{array}$ & $\begin{array}{c}\text { Significant } \\
\text { pain reduction }\end{array}$ \\
\hline Parecoxib & Intramuscular & Sun [58] & 2019 & 101 & Men & Rigid & Yes \\
\hline Diclofenac & Intrarectal & Nadeem [59] & 2016 & 60 & Men & Flexible & Yes \\
\hline Zaltoprofen & Oral & Komiya [60] & 2009 & 40 & Men & Rigid & Yes \\
\hline Pipemidic acid & Oral & Yuri [61] & 2016 & 80 & Both & No data & Yes \\
\hline Phenazopyridine & Oral & Yuri [61] & 2016 & 80 & Both & No data & Yes \\
\hline Diclofenac & Oral & Yuri [61] & 2016 & 80 & Both & No data & Yes \\
\hline Alprazolam & Oral & Ozkan [62] & 2017 & 86 & Men & Flexible & Yes \\
\hline Midazolam & Intravenous & Song [63] & 2007 & 80 & Both & Both & Yes \\
\hline Remifentanil-dexmedetomidine & Intravenous & Arpaci [64] & 2013 & 40 & Both & No data & Yes \\
\hline Remifentanil-midazolam & Intravenous & Arpaci [64] & 2013 & 40 & Both & No data & Yes \\
\hline Ketamine & $\begin{array}{c}\text { Intraurethral } \\
\text { (possible cystitis) }\end{array}$ & Moharari [65] & 2010 & 60 & Men & Rigid & Yes \\
\hline Dexmedetomidine-ketamine & Intravenous & Modir [67] & 2020 & 60 & Both & No data & Yes \\
\hline Acetaminophen & Oral/Intravenous & Kor [68] & 2020 & 3566 & Both & No data & Yes \\
\hline Sodium bicarbonate (Ural) & Oral & Wong [69] & 2011 & 300 & Both & Flexible & No \\
\hline
\end{tabular}


Table 7. Other methods of pain reduction during cystoscopy

\begin{tabular}{|c|c|c|c|c|c|c|}
\hline Method & $\begin{array}{l}\text { Name of first } \\
\text { author }\end{array}$ & $\begin{array}{c}\text { Year } \\
\text { of publication }\end{array}$ & $\begin{array}{l}\text { Number } \\
\text { of patients }\end{array}$ & Gender & $\begin{array}{l}\text { Type } \\
\text { of cystoscopy }\end{array}$ & $\begin{array}{l}\text { Significant } \\
\text { pain reduction }\end{array}$ \\
\hline Hypnosis & Tezcan [70] & 2021 & 90 & Men & Rigid & Yes \\
\hline Heating pad & $\operatorname{Kim}[71]$ & 2019 & 74 & Women & Rigid & Yes \\
\hline Glandular lidocaine injection & Gooran [72] & 2017 & 156 & Men & Rigid & Yes \\
\hline Hand-holding & Kwon [73] & 2018 & 86 & Men & Flexible & Yes \\
\hline $\begin{array}{l}\text { Transcutaneous electrical nerve } \\
\text { stimulation }\end{array}$ & Hruby [74] & 2006 & 148 & Both & Flexible & No \\
\hline Anesthesia of posterior urethra & Poletajew [75] & 2017 & 127 & Men & Rigid & No \\
\hline
\end{tabular}

remains controversial and intravenous administration of dexmedetomidine-ketamine is a recommended method providing efficient anesthesia and sedation [67]. Ketamine is mainly contraindicated in patients with heart diseases, due to hypertension caused by the drug.

Moreover, other drugs can also be used successfully, such as pipemidic acid, phenazopyridine and paracetamol $[61,68]$. A comparison between the oral administration of pipemidic acid, phenazopyridine and diclofenac indicated that pipemidic acid was superior to the other two drugs (based on the VAS score) [61]. Pipemidic acid and phenazopyridine are contraindicated in patients with severe renal and hepatic insufficiencies.

Finally, a study comparing oral and intravenous paracetamol use in ambulatory CS showed no difference in pain levels, with more complications after intravenous administration of acetaminophen [68]. This leads to the conclusion that parenteral administration of analgesics should be avoided unless necessary.

Unfortunately, the research concerning sodium bicarbonate proved that it does not lower the pain associated with urination after CS [69].

\section{Other methods}

Despite the abundance of previously described ways of pain management, there are still a few that do not fall directly into any of the previously mentioned categories (Table 7).

One of the most recent studies published in 2021 legitimated hypnosis as helpful in reducing pain and anxiety caused by rigid CS (based on VAS, STAI and hemodynamic parameters) [70]. Application of heating pads to the women's sacra was proved effective in rigid CS as well (based on VAS, STAI and hemodynamic parameters) [71]. In men, the additional injection of lidocaine into the glans penis before the procedure served a major role in pain level reduction (based on VAS score) [72]. Lastly, even holding the patient's hand during CS played a significant role in lowering the pain and improving the patient's comfort (based on VAS and STAI scores) [73].

On the other hand, transcutaneous electrical nerve stimulation and additional anesthesia of the posterior urethra did not provide any benefit in pain reduction (based on VAS score, overall pain intensity assessed on a Likert scale and the need for analgesics during $6 \mathrm{~h}$ after the procedure) $[74,75]$.
The diversity of these methods and their effectiveness prove that CS is connected not only with physical pain, but also with psychological discomfort.

\section{Conclusions}

This review focused on a variety of possible methods of pain reduction during CS. Lidocaine gel should be used until it is undoubtedly proven ineffective. In order to increase patients' comfort it needs to be cold and instilled slowly 15 minutes before the procedure. Micturition and provision of high irrigation pressure during the insertion of the scope may be also helpfull in males. Analgesic drugs benefit patients undergoing CS. Distractions, such as video, music, stress ball or self-visualization might alleviate the pain. Additionally, nitrous oxide, heating pads, hand holding, hypnosis or lidocaine injection into the glans have been proven effective. Sodium bicarbonate, transcutaneous nerve stimulation and additional anesthesia of the posterior urethra do not lower pain levels during CS.

\section{The authors declare no conflict of interest.}

\section{References}

1. Engelsgjerd JS, Deibert CM. Cystoscopy. In: StatPearls [Internet]. Treasure Island (FL): StatPearls Publishing.

2. Yerlikaya G, Laml T, Elenskaia K, et al. Pain perception during outpatient cystoscopy: a prospective controlled study. Eur J Obstet Gynecol Reprod Biol 2014; 173: 101-105.

3. Seklehner S, Remzi M, Fajkovic H, et al. Prospective multi-institutional study analyzing pain perception of flexible and rigid cystoscopy in men. Urology 2015; 85: 737-741.

4. Krajewski W, Zdrojowy R, Wojciechowska J, et al. Patient comfort during flexible and rigid cystourethroscopy. Wideochir Inne Tech Maloinwazyjne 2016; 11: 94-97.

5. Krajewski W, Kościelska-Kasprzak K, Rymaszewska J, Zdrojowy R How different cystoscopy methods influence patient sexual satisfaction, anxiety, and depression levels: a randomized prospective trial. Qual Life Res 2017; 26: 625-634.

6. Pillai PL, Sooriakumaran P. Flexible cystoscopy: a revolution in urological practice. Br J Hosp Med (Lond) 2009; 70: 583-585.

7. Burke DM, Shackley DC, O'Reilly PH. The community-based morbidity of flexible cystoscopy. BJU Int 2002; 89: 347-349.

8. Ellerkmann RM, Dunn JS, McBride AW, et al. A comparison of anticipated pain before and pain rating after the procedure in patients who undergo cystourethroscopyy. Am J Obstet Gynecol 2003; 189: 66-69.

9. Greenstein A, Greenstein I, Senderovich S, Mabjeesh NJ. Is diagnostic cystoscopy painful? Analysis of 1,320 consecutive procedures. Int Braz J Urol 2014; 40: 533-538. 
10. Casteleijn NF, Vriesema JL, Stomps SP, et al. The effect of office based flexible and rigid cystoscopy on pain experience in female patients. Investig Clin Urol 2017; 58: 48-53.

11. Aaronson DS, Walsh TJ, Smith JF, et al. Meta-analysis: does lidocaine gel before flexible cystoscopy provide pain relief? BJU Int 2009; 104: 506-510.

12. Raskolnikov D, Brown B, Holt SK, et al. Reduction of pain during flexible cystoscopy: a systematic review and meta-analysis. J Urol 2019; 202: 1136-1142.

13. Patel AR, Jones JS, Babineau D. Lidocaine $2 \%$ gel versus plain lu bricating gel for pain reduction during flexible cystoscopy: a meta-analysis of prospective, randomized, controlled trials. J Uro 2008; 179: 986-990.

14. Chitale S, Hirani M, Swift L, Ho E. Prospective randomized cross over trial of lubricant gel against an anaesthetic gel for outpatient cystoscopy. Scand J Urol Nephrol 2008; 42: 164-167.

15. Akkoç A, Kartalmış M, Aydın C, et al. 2\% Lidocaine gel or plain lubricating gel: which one should be used in male flexible cystoscopy? Turkish J Urol 2016; 42: 92-96.

16. Cano-Garcia MDC, Casares-Perez R, Arrabal-Martin M, et al. Use of Llidocaine $2 \%$ gel does not reduce pain during flexible cystoscopy and is not cost-effective. Urol J 2015; 12: 2362-2365.

17. Dougher E, Zoorob D, Thomas D, et al. the effect of lidocaine gel on pain perception during diagnostic flexible cystoscopy in women a randomized control trial. Female Pelvic Med Reconstr Surg 2019; 25: 178-184.

18. Rappaport YH, Beberashvili I, Zisman A, Stav K. Is meatal analgesia necessary for pain reduction during cystoscopy in females? A prospective randomized study. Urology 2020; 146: 79-82.

19. Carrion A, García-Cruz E, Fernandez C, et al. Prior lubrication of the urethra does not reduce pain perception in men undergoing flexible cystoscopy. Urol Int 2016; 97: 392-396.

20. Goldfischer ER, Cromie WJ, Karrison TG, et al. Randomized, prospective, double-blind study of the effects on pain perception of lidocaine jelly versus plain lubricant during outpatient rigid cys toscopy. J Urol 1997; 157: 90-94.

21. Goktug HNG, Ozturk U, Sener NC, et al. Do lubricants with $2 \%$ lido caine gel have an effect on patient comfort in diagnostic cystosco py? Adv Clin Exp Med Off 2014; 23: 585-587.

22. Vasudeva P, Kumar A, Kumar N, et al. Effect of intraurethral dwell time of local anesthetic jelly on pain perception in men undergoing outpatient rigid cystoscopy: a randomized prospective study. J Endourol 2014; 28: 846-849.

23. Choe JH, Kwak KW, Hong JH, Lee HM. Efficacy of lidocaine spray as topical anesthesia for outpatient rigid cystoscopy in women a prospective, randomized, double-blind trial. Urology 2008; 71: 561-566.

24. Demir E, Kilciler M, Bedir S, Erken U. Patient tolerance during cystoscopy: a randomized study comparing lidocaine hydrochloride gel and dimethyl sulfoxide with lidocaine. J Endourol 2008; 22: 1027-1029.

25. Li H, Cheng Y, Li J, et al. NaHCO3-buffered lidocaine gel for outpatient rigid cystoscopy in men. J Perianesth Nurs 2016; 31: 154-157.

26. Choong S, Whitfield HN, Meganathan V, et al. A prospective, randomized, double-blind study comparing lignocaine gel and plain lubricating gel in relieving pain during flexible cystoscopy. Br J Urol 1997; 80: 69-71.

27. Holmes M, Stewart J, Rice M. Flexible cystoscopy: is the volume and content of the urethral gel critical? J Endourol 2001; 15: 855-858.

28. Panach-Navarrete J, Martínez-Jabaloyas JM. Is a retention time after the instillation of anesthetic lubricant necessary when performing male flexible cystoscopy? J Endourol 2015; 29: 223-225.

29. Losco G, Antoniou S, Mark S. Male flexible cystoscopy: does waiting after insertion of topical anaesthetic lubricant improve patient comfort? BJU Int 2011; 108: 42-44.

30. Herr HW, Schneider M. Immediate versus delayed outpatient flexible cystoscopy: final report of a randomized study. Can J Urol 2001; 8: 1406-1408.

31. McFarlane N, Denstedt J, Ganapathy S, Razvi H. Randomized trial of $10 \mathrm{~mL}$ and $20 \mathrm{~mL}$ of $2 \%$ intraurethral lidocaine gel and placebo in men undergoing flexible cystoscopy. J Endourol 2001; 15: 541-544.
32. Ho KJ, Thompson TJ, O’Brien A, et al. Lignocaine gel: does it cause urethral pain rather than prevent it? Eur Urol 2003; 43: 194-196.

33. Thompson TJ, Thompson N, O'Brien A, et al. To determine whether the temperature of $2 \%$ lignocaine gel affects the initial discomfort which may be associated with its instillation into the male urethra. BJU Int 1999; 84: 1035-1037.

34. Goel R, Aron M. Cooled lignocaine gel: does it reduce urethral discomfort during instillation? Int Urol Nephrol 2003; 35: 375-377.

35. Khan MA, Beyzade B, Tau W, et al. Effect of the rate of delivery of lignocaine gel on patient discomfort perception prior to performing flexible cystoscopy. Urol Int 2002; 68: 164-167.

36. Xie Y, Wang W, Yan W, et al. Efficacy of urination in alleviating man's urethral pain associated with flexible cystoscopy: a single-center randomized trial. BMC Urol 2020; $20: 2$.

37. Sarkar D, Kapoor K, Pal DK. Pain and anxiety assessment during cystourethroscopy in males using voiding instruction: a prospective, randomized controlled study. Urol Ann 2019; 11: 139-142.

38. Gunendran T, Briggs RH, Wemyss-Holden GD, Neilson D. Does in creasing hydrostatic pressure ("bag squeeze") during flexible cystoscopy improve patient comfort: a randomized, controlled study. Urology 2008; 72: 255-259.

39. Zhang Z-S, Wang X-L, Zeng S-X, et al. Pressure Makes Pleasure: A Preliminary Study of Increasing Irrigation Pressure of Flexible Cystoscopy Improves Male Patient Comfort by an Easy Way. J Endourol 2015; 29(12): 1361-1365.

40. Berajoui MB, Aditya I, Herrera-Caceres J, et al. A prospective randomized controlled trial of irrigation "bag squeeze" to manage pain for patients undergoing flexible cystoscopy. J Urol 2020; 204: 1012-1018.

41. Young A, Ismail M, Papatsoris AG, et al. Entonox ${ }^{\circledR}$ inhalation to reduce pain in common diagnostic and therapeutic outpatient urological procedures: a review of the evidence. Ann R Coll Surg Engl 2012; 94: 8-11.

42. Calleary JG, Masood J, Van-Mallaerts R, Barua JM. Nitrous oxide inhalation to improve patient acceptance and reduce procedure related pain of flexible cystoscopy for men younger than 55 years. J Urol 2007; 178: 184-188.

43. Gopalakrishna A, Bole R, Lipworth R, et al. Use of nitrous oxide in office-based urologic procedures: a review. Urology 2020; 143: 33-41.

44. Gupta S, Das SK, Jana D, Pal DK. Distraction during cystoscopy to reduce pain and increase satisfaction: randomized control study between real-time visualization versus listening to music versus combined music and real-time visualization. Urol Ann 2019; 11: 33-38

45. Gezginci E, lyigun E, Kibar Y, Bedir S. Three distraction methods for pain reduction during cystoscopy: a randomized controlled tria evaluating the effects on pain, anxiety, and satisfaction. J Endourol 2018; 32: 1078-1084.

46. Walker MR, Kallingal GJS, Musser JE, et al. Treatment efficacy of virtual reality distraction in the reduction of pain and anxiety during cystoscopy. Mil Med 2014; 179: 891-896.

47. González-Padilla DA, González-Díaz A, García-Gómez B, et al. Cystoscopy real-time self-visualization and its impact in patient's pain perception. J Endourol 2019; 33: 309-313.

48. Patel AR, Jones JS, Babineau D. Impact of real-time visualization of cystoscopy findings on procedural pain in female patients. J Endourol 2008; 22: 2695-2698.

49. Zhang Z, Tang L, Wang X, et al. Seeing is believing: a randomized controlled study from China of real-time visualization of flexible cystoscopy to improve male patient comfort. J Endourol 2011; 25: $1343-1346$

50. Soomro KQ, Nasir AR, Ather MH. Impact of patient's self-viewing of flexible cystoscopy on pain using a visual analog scale in a randomized controlled trial. Urology 2011; 77: 21-23.

51. Patel AR, Jones JS, Angie S, Babineau D. Office based flexible cys toscopy may be less painful for men allowed to view the procedure. J Urol 2007; 177: 1843-1845.

52. Cornel EB, Oosterwijk E, Kiemeney LA. The effect on pain experienced by male patients of watching their office-based flexible cystoscopy. BJU Int 2008; 102: 1445-1446. 
53. Kesari D, Kovisman V, Cytron S, Benjamin J. Effects on pain and anxiety of patients viewing their cystoscopy in addition to a detailed explanation: a controlled study. BJU Int 2003; 92: 751-752.

54. García-Perdomo HA, Montealegre Cardona LM, Cordoba-Wagner MJ, Zapata-Copete JA. Music to reduce pain and anxiety in cystoscopy: a systematic review and meta-analysis. J Complement Integr Med 2018; 16: /j/jcim.2019.16.issue-3/jcim-2018-0095/jcim-20180095.xml.

55. Kyriakides R, Jones P, Geraghty R, et al. Effect of music on outpatient urological procedures: a systematic review and meta-analysis from the european association of urology section of uro-technology. J Urol 2018; 199: 1319-1327.

56. Ölçücü MT, Yılmaz K, Karamık K, et al. Effects of listening to binaural beats on anxiety levels and pain scores in male patients undergoing cystoscopy and ureteral stent removal: a randomized placebo-controlled trial. J Endourol 2021; 35: 54-61.

57. Gezginci E, Bedir S, Ozcan C, lyigun E. Does watching a relaxing video during cystoscopy affect pain and anxiety levels of female patients? A randomized controlled trial. Pain Manag Nurs 2020: S1524-9042(20)30173-9.

58. Sun J-Y, Song Z-S, Zhang X-P, Xiao X-Y. Efficacy and Safety of COX-2 inhibitor parecoxib for rigid cystoscopy-related pain management in male patients: a prospective, randomized and controlled study. Curr Med Sci 2019; 39: 94-98.

59. Nadeem M, Ather MH. Effect of diclofenac suppository on pain control during flexible cystoscopy-A randomized controlled trial. F1000Res 2016; 5: 2834

60. Komiya A, Endo T, Kobayashi M, et al. Oral analgesia by non-steroidal anti-inflammatory drug zaltoprofen to manage cystoscopy-related pain: a prospective study. Int J Urol Off J Japanese Urol Assoc 2009; 16: 874-880.

61. Yuri P, Ali Z, Rasyid N, Birowo P. Effects of pipemidic acid, phenazopyridine $\mathrm{hcl}$ and sodium diclofenac on pain perception following endoscopic urological surgery: double-blinded randomized-controlled trial. Acta Med Indones 2016; 48: 184-192.

62. Ozkan TA, Koprulu S, Karakose, A et al. Does using alprazolam during outpatient flexible cystoscopy decrease anxiety and pain? Arch Esp Urol 2017; 70: 800-805.

63. Song YS, Song ES, Kim KJ, et al. Midazolam anesthesia during rigid and flexible cystoscopy. Urol Res 2007; 35: 139-142.

64. Arpaci AH, Bozkırlı F. Comparison of sedation effectiveness of remifentanil-dexmedetomidine and remifentanil-midazolam combinations and their effects on postoperative cognitive func tions in cystoscopies: a randomized clinical trial. J Res Med Sci Off J Isfahan Univ Med Sci 2013; 18: 107-114.

65. Moharari RS, Najafi A, Khajavi MR, et al. Intraurethral instillation of ketamine for male rigid cystoscopy. J Endourol 201; 24: 2033-2036.

66. Yip SKH, Ng CF. Re: intraurethral instillation of ketamine for male rigid cystoscopy (from: Moharai RS, Najafi A, Khajavi MR, et al. J Endourol 2010; 24:2033-2036). J Endourol 2011; 25: 1677 -1678.

67. Modir H, Moshiri E, Yazdi B, et al. Efficacy of dexmedetomidine-ketamine vs. fentanylketamine on saturated oxygen, hemodynamic responses and sedation in cystoscopy: a doubleblinded randomized controlled clinical trial. Med Gas Res 2020; 10: 91-95.

68. Kor TM, Naranjo J, Deljou A, et al. Intravenous versus oral acet aminophen in outpatient cystoscopy procedures: retrospective comparison of postoperative opioid requirements and analgesia scores. Am Surg 2020; 86: 1691-1696.

69. Wong L-M, Huang JG, Yong TL, et al. Does sodium bicarbonate re duce painful voiding after flexible cystoscopy? A prospective, randomized, double-blind, controlled trial. BJU Int 2011; 108: 718-721.

70. Tezcan B, Ademoğlu D, Can M, et al. A randomized clinical tria on the effect of hypnosis on anxiety and pain in rigid cystoscopy patients. J Endourol 2021; 35: 47-53.

71. Kim HJ, Kim JW, Park HS, et al. The use of a heating pad to reduce anxiety, pain, and distress during cystoscopy in female patients. Int Urogynecol J 2019; 30: 1705-1710.

72. Gooran S, Pourfakhr P, Bahrami S, et al. A randomized control trial comparing combined glandular lidocaine injection and intraurethral lidocaine gel with intraurethral lidocaine gel alone in cystoscopy and urethral dilatation. Urol J 2017; 14: 4044-4047.
73. Kwon W-A, Lee JW, Seo HK, et al. Hand-holding during cystoscopy decreases patient anxiety, pain, and dissatisfaction: a pilot randomized controlled trial. Urol Int 2018; 100: 222-227.

74. Hruby G, Ames C, Chen C, et al. Assessment of efficacy of transcutaneous electrical nerve stimulation for pain management during office-based flexible cystoscopy. Urology 2006; 67: 914-917.

75. Poletajew S, Bender S, Pudełko P, et al. Anaesthesia of the posterior urethra and pain reduction during cystoscopy - a randomized controlled trial. Wideochir Inne Tech Maloinwazyjne 2017; 12: 75-80.

\section{Address for correspondence}

\section{Jan Łaszkiewicz}

Medical University of Lodz

4 Kościuszki Av.

90-419 Łódź, Poland

e-mail: jasieklaszkiewicz@gmail.com

Submitted: 20.03 .2021

Accepted: 24.04.2021 